\title{
PAGGAMIT NG "BASA-PANG-UNAWA APP" ISANG KAGAMITAN BILANG INTERBENSIYON SA PAGKATUTO SA PAGGANAP NG MGA MAG-AARAL
}

\author{
Glenn D. Nonggod \\ Master of Arts in Filipino, Laguna State Polytechnic University, Santa Cruz, Laguna, Philippines
}

Article DOI: $\underline{\text { https://doi.org/10.36713/epra7669 }}$

DOI No: 10.36713/epra7669

\begin{abstract}
Abstrak

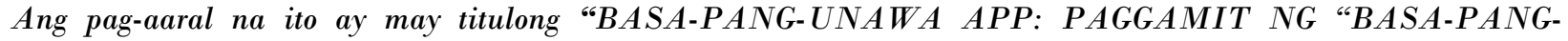
UNAWA APP" ISANG KAGAMITAN BILANG INTERBENSIYON SA PAGKATUTO SA PERFORMANS NG MGA MAG-AARAL

Layunin ng pag-aaral na ito na mabatid ang kabisaan ng aplikasyong Basa-Pang-unawa App bilang interbensiyon sa pagkatuto sa performance ng mga mag-aaral ng asignaturang Filipino sa mga mag-aaral ng ikapitong antas (7) sa Taong Panuruan 2020-2021.

Ang pag-aaral na ito ay mahalaga sapagkat naisin nitong mabatid ang pagkatuto ng mga mag-aaral at mapataas ang antas at lebel ng kanilang performans at pagkatuto sa pamamagitan ng paggamit ng Basa-Pangunawa App. Sa pamamagitan nito mas naging kawili-wili ang pagkatuto ng mag mag-aral. Nalalaman din ang resulta ng paunang pagsusulit at panapos na pagsusulit; malaman kung may makabuluhang pagkakaiba ang antas ng pagganap ng mga mag-aaral batay sa pauna at panapos na pagsusulit; at mabatid kung mayroon bang makabuluhang relasyon ang paggamit ng Basa-Pang-unawa App bilang interbensiyon sa pagkatuto sa performans ng mga mag-aaral

Deskriptibong pamamaraan ang ginamit ng mananaliksik upang makuha ang mga kinakailangang datos. Apatnapung(40) mga mag-aaral ang naging respondente ng pag-aaral mula sa Pag-asa National High School na ginamitan ng "Purposive Sampling Technique".

Sa pagsasagawa ng pag-aaral, gumamit ang mananaliksik ng paunang pagsusulit, panapos na pagsusulit at talatanungan.

Batay sa nakuhang mga datos, ang mga nilalaman, pagsasanay at layunin nito kapwa lubhang mataas.

Ukol sa kinalabasan ng antas ng pauna at panapos na pagsusulit ng mga mag-aaral, ito ay may markang katamtamang taas. Nangangahulugang walang makabuluhang pagkakaiba ng antas ng pagganap ng mga mag-aaral batay sa pauna at panapos na pagsusulit.

Ang haypotesis na walang makabuluhang pagkakaiba ang antas ng pagganap ng mga mag-aaral batay sa pauna at panapos na pagsusulit ay hindi tinanggap sapagkat nagkaroon ng makabuluhang pagkakaiba pagitan nito. Ito ay nangangahulugan na naging mabisa ang paggamit ng nasabing makabagong pandulog at estratehiya sa pagtuturo ng asignaturang Filipino.

Ang haypotesis walang makabuluhang epekto ang paggamit ng Basa-Pang-unawa App bilang interbensiyon sa Pagkatuto sa Performans ng mga mag-aaral sa Asignaturang Filipino sa pagganap ng mga mag-aaral ay hindi tinanggap. Samakatuwid, makabuluhang kaugnayan sa pagitan nito. Nangangahulugan ito na mahalaga ang paggamit ng Basa-Pang-unawa App bilang interbensiyon sa pagkatuto sa performans ng mga mag-aaral.
\end{abstract}




\section{SJIF Impact Factor 2021: 8.013| ISI I.F.Value:1.241| Journal DOI: 10.36713/epra2016 ISSN: 2455-7838(Online) EPRA International Journal of Research and Development (IJRD)}

\section{PANIMULA}

Guro ang susi sa lahat ng suliranin ukol sa mabisang pagtuturo. Kung baga sa isang manggagamot nararapat pulsuhan ng guro ang kaniyang mga magaaral damhin at pakinggan ang tibok ng kanilang puso, pag-aralan ang sanhi ng kanilang karamdaman bago lapatan ng kaukulang lunas. Tungkulin ng isang guro ang magturo at magabayan nang maayos ang mga magaaral, sapagkat ang pagiging guro ay hindi lamang isang propesyon bagkus sila ang magsisilbing mitsa para sa kinabukasan ng mga mag-aaral.

Ayon kay Lacson (2020), Ang isang guro ay nararapat na makapagplano ng mga estratehiya at pamamaraan na makapagbibigay- daan tungo sa produktibong resulta sa kakayahan at kasanayan ng mga magaaral. Sinasabing ang pagtuturo ay isang sining at ang guro na siyang nagtuturo ang siyang gumaganap bilang direktor sa buhay kanyang mga mag-aaral. Bilang isang guro, may masalimuot na landas ang pagdaraanan niya bago mahubog ang buong pagkatao ng kanyang mag-aaral. Ang guro ang siyang nagbibigay ng direksyon sa kabataan na itinuturing na pag-asa ng bayan. Siya ang magsisilbing liwanag sa buhay ng kanyang mga mag-aaral na nagsisilbing malaking hamon sa mga guro. Upang mapagtagumpayan ang hamong ito, patuloy na tumutuklas ang mga guro ng iba't ibang makabagong pamamaraan, dulog, estratehiya at pagsasanay na papasa sa panlasa ng mga mag-aaral na buong-pusong yayakapin at tatanggapin.

Isang pag-aaral sa $\mathrm{La}$ Consolacion College Tanauan (2018), na may pamagat na "Epekto ng Multimedia sa Pang-akademikong Kasanayan ng mga mag-aaral sa Departamento ng Hayskul", ang multimedia ay dinisenyo upang mapagaan ang proseso ng pagtuturo at pagkatuto. $\mathrm{Sa}$ pamamagitan ng multimedia, nagiging kapanapanabik, nakagaganyak at natutulungan ang mga mag-aaral na matuto sa makabagong paraan. Makikita sa gumagamit ng multimedia ang mga totoong mundo sa pamamagitan ng mga tunog mga larawan at bidyo na maaaring hindi nararanasan ng mga mag-aaral sa tradisyunal na paraan ng pagtuturo ng guro. Tumataas din ang antas ng interaksyon ng mga mag-aaral. Hindi na sila pasibo kundi mga mag-aaral nang aktibong nakikilahok sa mga gawain.

Ang mga rekurso ng multimedia ay makatutulong sa mga gurong lumilikha ng mga gawain o karanasan sa pagkatuto ng bawat indibidwal ng magaaral. Ang mga gawain at karanasang ito ay magpapakilala sa pagpapahalaga ng mga kakayahan ng bawat mag-aaral.
Sa mabilis na pagbabago ng sanhi ng mga makabagong teknolohiya, ang mga guro ay magkakaroon ng kaalaman at kakayahang panteknolohiya upang makaagapay sa panahon ng digital. Sa larangan ng edukasyon ngayon, may mga indibidwal na nagtataglay ng kagalingan at kakayahan sa pagtuturo gamit ang impormasyon sa komunikasyong panteknolohiya o yaong tinatawag nating Information and Communication Technology (ICT).

Sa makabagong panahon, makabago rin ang paraan ng pagtuturo at pagkatuto ng mga mag-aaral. Nariyan ang iba't ibang uri ng application na sa pagkatuto na mas nakakapukaw sa interes na mga magaaral. Ang mga ito ay dinisenyo upang mas mapalawak ang konsepto ng pagtuturo at mas madaling maunawaan ang aralin.

Bilang isang guro sa asignaturang Filipino, kapansin-pansin na marami sa mga mag-aaral ngayon ang nahihirapang bumasa at unawain ang kanilang binabasa. Kung kaya't ang dahilan ng mananaliksik upang bigyan ng solusyon ang suliraning mataas ang lebel mga mag-aaral sa pag-unawa ng kanilang binabasa sa pamamagitan ng paggamit ng "Basa-Pangunawa App" sa antas sekundarya.

\section{KAGAMITAN AT PAMAMARAAN}

Ang disenyong ginamit ng mananaliksik sa pagaaral na ito ay deskriptibong paraan. Ang palarawang pananaliksik (Descriptive Method) ay mga kaganapan sa pag-aaral na ginagamitan ng palarawang pananaliksik ay kinapapalooban ng pagtatala, paglalarawan, pagpapakahulugan, pagsusuri at paghahambing. Layunin ng ganitong disenyo na sistematikong mailarawan ang sitwasyon at kundisyon nang makatotohanan at buong katiyakan.

Sa pag-aaral na ito, ang mga tagatugon na ginamit ay ang mga mag-aaral sa ikapitong baitang na nagmula sa Pag-asa National High School, City of Dasmrinas, Cavte. Ang tagatugon ay binubuo ng apatnapu (40) na mag-aaral at (10) na mga guro na may kabuuang bilang na limampu (50). Sa pagsasagawa ng pananaliksik na ito, ang mananaliksik ay gumamit ng "Purposive Sampling Technique".

Sa pagsasagawa ng pananaliksik na ito, ang mananaliksik ay gumamit ng "Purposive Sampling Technique".

Ang mananaliksik ay may mga hakbang na isinagawa upang makakalap ng mga kinakailangang datos sa pag-aaral. Mula sa pagbabasa ng piling aklat sa sekundarya at piling pahina sa internet ay naging mapanuri ang mananaliksik sa pangangalap ng datos upang maging matagumpay at maging kapaki- 


\section{SJIF Impact Factor 2021: 8.013| ISI I.F.Value:1.241| Journal DOI: 10.36713/epra2016 ISSN: 2455-7838(Online) EPRA International Journal of Research and Development (IJRD)}

pakinabang ang isang pag-aaral. Gumamit ang mananaliksik ng isang Basa-Pang-unawa na kung saan isinangguni muna sa sampung (10) guro upang magkaroon ito ng balidasyon. Pagkatapos ng balidasyon, maaari na itong ipagamit sa aapatnapung (40) mag-aaral na tagatugon ng pag-aaral upang malaman ang epekto nito sa pagkatuto ng mga magaaral. Ang ginamitin din ng instrumento sa pananaliksik ay talatanungan sa anyong pagsusulit. Sa pagbuo ng talatanungan sa pananaliksik na ito, ang mananaliksik ay bumatay sa mga piling akda na nasa tekstong pinag-aaralan sa asignaturang Filipino na nagmula. Ang talatanungan ay binubuo ng tatlong bahagi: ang una sampung (10) aytem patungkol sa nilalaman. Ang ikalawang bahagi ay sampung (10) aytem patungkol naman sa pagsasanay at ang ikatlo bahagi ay sampung (10)aytem na pumatungkol naman sa layunin na may kabuuang tatlumpung (30) aytem para sa ginawang talatanungan. Matapos na magawa ang talatanungan, ito ay isinangguni sa gurong nagtuturo rin ng asignaturang Filipino at sa tatlong guro na ginamit sa panelist ng proposal defense. Iminungkahi ng mga guro ang balidasyon ng talatanungan sapagkat naging maayos ang pagkakabuo ng mga tanong. Matapos ang balidasyon, gumawa ang mananaliksik ng isang lihampahintulot sa tanggapan ng punungguro I na si Gng. Rea C. Bunan at sa ulongguro III na si Gng. Jedie A. Mendoza na namumuno sa departamento ng Filipino upang maisagawa ang pagaaral sa mga mag-aaral sa ikapitong baitang ng Pag-asa National High School. Nang mapagtibay ang mga liham-pahintulot para sa pananaliksik sa paggamit ng Bisa-Pang-unawa App bilang interbensiyon, nagpasagot ang mananaliksik sa mga mag-aaral sa ikapitong-baitang. Pagkatapos ng pagbibigay ng paunang pagsusulit gamit ang google form. Pagkatapos nito ang mga tagatugon ay nagkaroon sila ng pagsasanay sa iba't ibang antas ng nasabing aplikasyon. Matapos na makapagturo ng guro ay sinundan ito ng pagbibigay panapos na pagsusulit. Katulad ng isinagawa sa paunang pagsusulit, ito ay pinaghambing din ng mananaliksik upang makita o matukoy kung may malaking pagkakaiba sa iskor sa naunang pagsusulit. Matapos bigyang-pagwawasto ang pinasagutang talatanungan, isa-isa itong itinala, inugnayan ng istadistika, sinuri at binigyan $\mathrm{ng}$ interpretasyon.

Ang mananaliksik ay bumuo ng Basa-PangUnawa bilang interbensiyon. Ang ginawang talatanungan ng mananaliksik ay ginamit bilang instrumento sa pagkalap ng datos. Layunin $\mathrm{ng}$ talatanungan na makagawa ng pagtataya sa mga eksperto sa asignatura, ang Guro I hanggang Guro III, Dalubguro at mag-aaral. Ang talatanungan ay may tatlong (3) bahagi. Ang nilalaman ng talatanungan ay sinagot ng mga guro sa Filipino at mag-aaral.

Ginamit ng mananaliksik ang mga pamamaraang istadistika upang mabigyan ng malinaw na pagsusuri, interpretasyon at pagtataya ang mga nakalap na datos. Upang matukoy ang resulta ng antas ng paggamit ng Basa-Pang-unawa App sa kraytiryang pang nilalaman, pagsasanay, at layunin ay Mean at standard deviation ay ginamit.

Samantalang sa antas ng paunang pagsusulit at panapos na pagsusulit ay ginamit din ang frequency percentage. Upang malaman kung mayroon bang makabuluhang eprkto ang paggamit ng Basa-Pangunawa App bilang interbensiyon sa pagkatuto ng mga mag- -aaral ay gumamit ng F-test.

\section{RESULTA AT DISKUSYON}

Ang Talahanayan 1 ay nagpapakita ng Antas ng paggamit ng Basa-Pang-unawa App bilang interbensiyon sa Pagkatuto batay sa Nilalamanay May lubhang mataas na antas ng pagtanggap sa pananaw ng mga mag-aaral.

Talahanayan 1. Antas ng paggamit ng Basa-Pang-unawa App bilang interbensiyon sa Pagkatuto batay sa Nilalaman

\begin{tabular}{|l|c|c|c|c|c|c|c|}
\hline \multirow{2}{*}{ Mga Pahayag } & \multicolumn{2}{|c|}{ Mag-aaral } & \multicolumn{2}{|c|}{ Guro } & \multicolumn{4}{|c|}{ Kabuoan } \\
\cline { 2 - 9 } & Mn & SD & Mn & SD & OM & SD & \multicolumn{2}{c|}{ Puna } \\
\hline $\begin{array}{l}\text { Mahusay ang presentasyon o pagkakalahad ng } \\
\text { nilalaman. }\end{array}$ & 4.38 & 1.02 & 4.70 & 0.48 & 4.45 & 0.94 & Lubos na sumasang-ayon \\
\hline $\begin{array}{l}\text { Ang nilalaman ng interbensyon ay malinaw na } \\
\text { makikita sa aplikasyon }\end{array}$ & 4.44 & 0.82 & 4.80 & 0.42 & 4.51 & 0.77 & Lubos na sumasang-ayon \\
\hline $\begin{array}{l}\text { Malinaw na nababasa ang nilalaman ng paksa mula } \\
\text { sa aplikasyon }\end{array}$ & 4.51 & 0.82 & 4.80 & 0.42 & 4.57 & 0.76 & Lubos na sumasang-ayon \\
\hline Maayos ang pagkakagawa ng mga graphics. & 4.56 & 0.75 & 4.60 & 0.52 & 4.57 & 0.71 & Lubos na sumasang-ayon \\
\hline Nabibigyang diin, maayos at malinaw ang diwa ng & 4.54 & 0.68 & 4.70 & 0.48 & 4.57 & 0.65 & Lubos na sumasang-ayon \\
\hline
\end{tabular}


SJIF Impact Factor 2021: 8.013| ISI I.F.Value:1.241| Journal DOI: 10.36713/epra2016 ISSN: 2455-7838(Online) EPRA International Journal of Research and Development (IJRD)

Volume: 6 | Issue: 7 | July 2021

- Peer Reviewed Journal

\begin{tabular}{|c|c|c|c|c|c|c|c|c|c|}
\hline \multicolumn{10}{|c|}{$\begin{array}{lllll}\text { bawat paksang } & \text { nakapaloob } & \text { sa } & \text { paggamit } & \text { ng } \\
\text { aplikasyon }\end{array}$} \\
\hline \multicolumn{3}{|c|}{ Nakabatay sa K-12 kurikulum ang aplikasyon. } & 4.49 & 0.76 & 4.70 & 0.48 & 4.53 & 0.71 & Lubos na sumasang-ayon \\
\hline \multicolumn{3}{|c|}{$\begin{array}{l}\text { Ang nilalaman ay sapat upang lubos na } \\
\text { maunawaan ang ang teksto. }\end{array}$} & 4.38 & 0.75 & 4.70 & 0.48 & 4.45 & 0.71 & Lubos na sumasang-ayon \\
\hline \multicolumn{3}{|c|}{$\begin{array}{l}\text { Sapat ang nakapaloob na aytem upang mapataas } \\
\text { ang kakayahan ng mga mag-aaral sa pag-unawa ng } \\
\text { teksto. }\end{array}$} & 4.44 & 0.85 & 4.70 & 0.48 & 4.49 & 0.79 & Lubos na sumasang-ayon \\
\hline \multicolumn{3}{|c|}{$\begin{array}{l}\text { Nahahasa ang kakayahan ng pagbasang ng mga } \\
\text { mag-aaral ula sa aplikasyon }\end{array}$} & 4.41 & 0.79 & 4.80 & 0.42 & 4.49 & 0.74 & Lubos na sumasang-ayon \\
\hline \multicolumn{3}{|c|}{$\begin{array}{l}\text { Nakaangkop sa ibat ibang kakayahan ng mag-aaral } \\
\text { batay sa nilalaman ng aplikasyon }\end{array}$} & 4.38 & 0.78 & 4.60 & 0.70 & 4.43 & 0.76 & Lubos na sumasang-ayon \\
\hline \multicolumn{10}{|c|}{$\begin{array}{l}\text { Overall Mean: } 4.51 \\
\text { Standard Deviation: } 0.752 \\
\text { Literal na paliwanag: } \text { Lubhang Mataas }\end{array}$} \\
\hline \multicolumn{10}{|c|}{ Palatandaan } \\
\hline Sukatan & Saklaw & \multicolumn{3}{|l|}{ Pur } & \multicolumn{5}{|c|}{ Literal na paliwanag } \\
\hline & $4.20-5.00$ & \multicolumn{3}{|l|}{ Lubos na sumasang-ayon } & \multicolumn{5}{|c|}{ Lubhang Mataas } \\
\hline 4 & $3.40-4.19$ & \multicolumn{3}{|l|}{ Sumasang-ayon } & \multicolumn{5}{|l|}{ Mataas } \\
\hline 3 & $2.60-3.39$ & \multicolumn{3}{|c|}{ Katamtamang Sumasang-ayon } & \multicolumn{5}{|c|}{ Katamtamang Taas } \\
\hline 2 & $1.80-2.59$ & \multicolumn{3}{|l|}{ Hindi sumasang-ayon } & \multicolumn{5}{|l|}{ Mababa } \\
\hline 1 & $1.00-1.79$ & \multicolumn{3}{|c|}{ Lubos na Hindi sumasang-ayon } & \multicolumn{5}{|c|}{ Lubos Mababa } \\
\hline
\end{tabular}

Ang Talahanayan 1 ay nagpapakita ng Antas ng paggamit ng Basa-Pang-unawa App bilang interbensiyon sa Pagkatuto batay sa Nilalamanay May lubhang mataas na antas ng pagtanggap sa pananaw ng mga mag-aaral, maayos ang pagkakagawa ng mga graphics ay nakakuha ng $(M=4.56, S D=0.75)$ at nabibigyang diin, maayos at malinaw ang diwa ng bawat paksang nakapaloob sa paggamit ng aplikasyon ay mayroong $(M=4.54, S D=0.68)$. Bagaman napansin na lubhang mataas na antas ng pagtanggap, ang pahayag na may pinakamababang marka ay mahusay ang presentasyon o pagkakalahad ng nilalaman, ang nilalaman ay sapat upang lubos na maunawaan ang ang teksto at nakaangkop sa ibat ibang kakayahan ng mag-aaral batay sa nilalaman $\mathrm{ng}$ aplikasyon ay mayroong $(M=4.38, S D=1.02,0.75$, 0.78).

At may lubhang mataas na antas ng pagtanggap sa pananaw ng mga guro, ang nilalaman $n g$ interbensyon ay malinaw na makikita sa aplikasyon, malinaw na nababasa ang nilalaman ng paksa mula sa aplikasyon at nahahasa ang kakayahan ng pagbasang ng mga mag-aaral ula sa aplikasyon ay nakakuha ng $(M=4.80, S D=0.42)$ at mahusay ang presentasyon $o$ pagkakalahad ng nilalaman, nabibigyang diin, maayos at malinaw ang diwa ng bawat paksang nakapaloob sa paggamit ng aplikasyon, nakabatay sa K-12 kurikulum ang aplikasyon, ang nilalaman ay sapat upang lubos na maunawaan ang ang teksto at sapat ang nakapaloob na aytem upang mapataas ang kakayahan ng mga magaaral sa pag-unawa ng teksto ay mayroong $(M=4.70$, $S D=0.48$ ). Bagaman napansin na lubhang mataas na antas ng pagtanggap, ang pahayag na may pinakamababang marka ay maayos ang pagkakagawa ng mga graphics at nakaangkop sa ibat ibang kakayahan ng mag-aaral batay sa nilalaman $n g$ aplikasyon ay mayroong $(M=4.60, S D=0.52,0.70)$.

Sa kabuuan ay may lubhang mataas na antas ng pagtanggap at sa pananaw ng mga tagatugon, malinaw na nababasa ang nilalaman ng paksa mula sa aplikasyon, maayos ang pagkakagawa ng mga graphics, at nabibigyang diin, maayos at malinaw ang diwa ng bawat paksang nakapaloob sa paggamit ng aplikasyon ay nakakuha ng $(M=4.57, S D=0.76,0.71$, 0.75 ) at nakabatay sa K-12 kurikulum ang aplikasyon ay mayroong $(M=4.53, S D=0.71)$. Bagaman napansin na lubhang mataas na antas ng pagtanggap, ang pahayag na may pinakamababang marka ay mahusay ang presentasyon o pagkakalahad ng nilalaman, ang nilalaman ay sapat upang lubos na maunawaan ang ang teksto at nakaangkop sa ibat ibang kakayahan ng mag-aaral batay sa nilalaman ng aplikasyo Nakaangkop sa ibat ibang kakayahan ng mag-aaral batay sa nilalaman $n g$ aplikasyon ay mayroong $(M=4.43, S D=0.76)$.

May kabuuang mean na 4.51, standard deviation na 0.752 at ipinapakita na ang antas ng paggamit ng Basa-Pang-unawa App bilang interbensiyon sa 


\section{SJIF Impact Factor 2021: 8.013| ISI I.F.Value:1.241| Journal DOI: 10.36713/epra2016 ISSN: 2455-7838(Online)}

\section{EPRA International Journal of Research and Development (IJRD)}

Volume: 6 | Issue: 7 | July 2021

- Peer Reviewed Journal

Pagkatuto batay sa Nilalaman ay may puna na lubos na sumasang-ayon at may literal na paliwanag na lubhang mataas.
Talahanayan 2 ay nagpapakita ng Antas ng paggamit ng Basa-Pang-unawa App bilang interbensiyon sa Pagkatuto batay sa Pagsasanay.

Talahanayan 2. Antas ng paggamit ng Basa-Pang-unawa App bilang interbensiyon sa Pagkatuto batay sa Pagsasanay

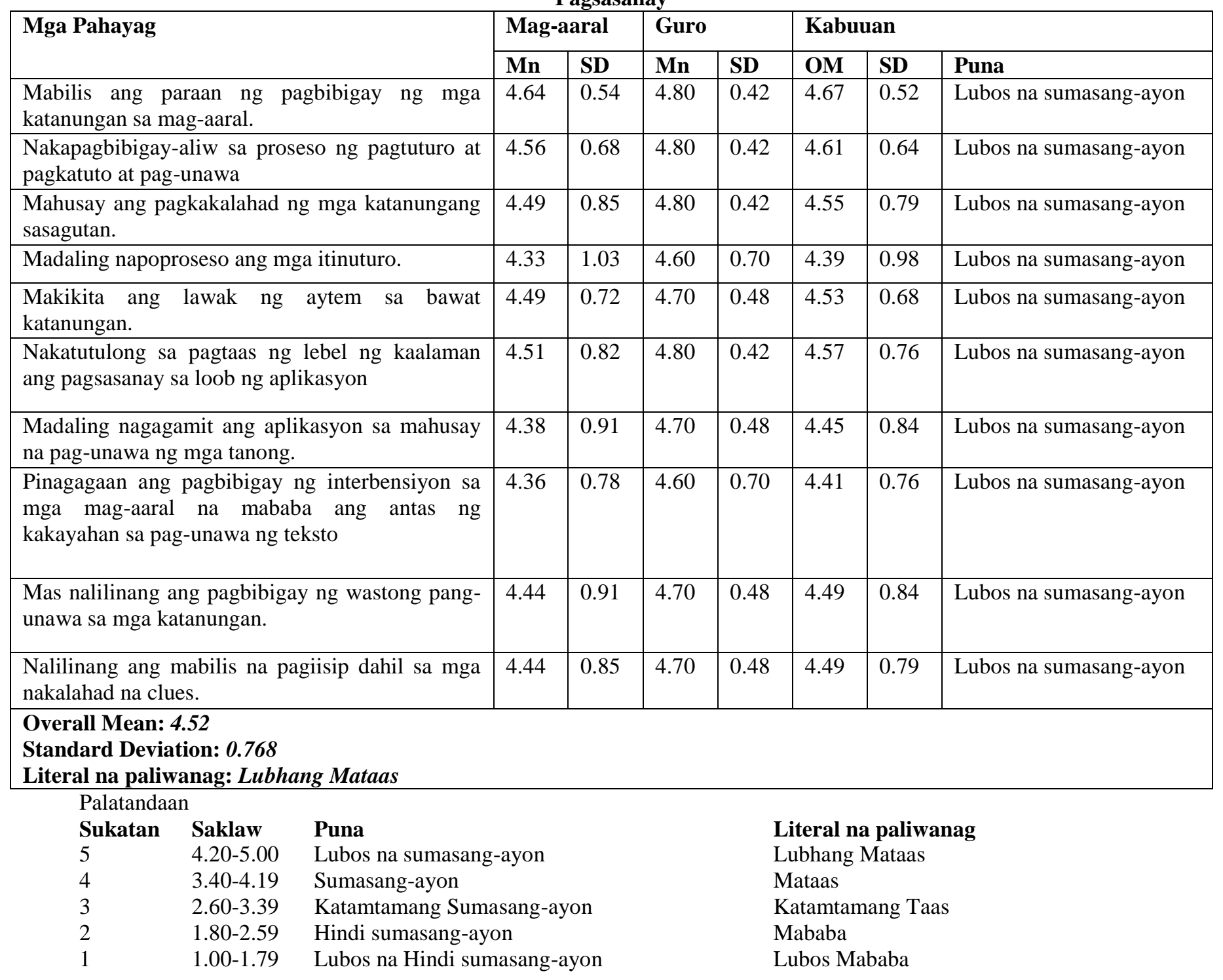

May lubhang mataas na antas ng pagtanggap sa pananaw ng mga mag-aaral, mabilis ang paraan ng pagbibigay ng mga katanungan sa mag-aaral ay nakakuha ng $(\mathrm{M}=4.64, \mathrm{SD}=0.54)$ at nakapagbibigayaliw sa proseso ng pagtuturo at pagkatuto at pag-unawa ay mayroong $(\mathrm{M}=4.56, \mathrm{SD}=0.68)$. Bagaman napansin na lubhang mataas na antas ng pagtanggap, ang pahayag na may pinakamababang marka ay madaling napoproseso ang mga itinuturo ay mayroong $(\mathrm{M}=4.33, \mathrm{SD}=1.03)$.

At may lubhang mataas na antas ng pagtanggap sa pananaw ng mga guro, mabilis ang paraan ng pagbibigay ng mga katanungan sa mag-aaral, nakapagbibigay-aliw sa proseso ng pagtuturo at pagkatuto at pag-unawa, mahusay ang pagkakalahad ng mga katanungang sasagutan at nakatutulong sa pagtaas ng lebel ng kaalaman ang pagsasanay sa loob ng 


\section{SJIF Impact Factor 2021: 8.013| ISI I.F.Value:1.241| Journal DOI: 10.36713/epra2016 ISSN: 2455-7838(Online) EPRA International Journal of Research and Development (IJRD)}

aplikasyon ay nakakuha ng $(\mathrm{M}=4.80, \mathrm{SD}=0.42)$ at makikita ang lawak ng aytem sa bawat katanungan, madaling nagagamit ang aplikasyon sa mahusay na pag-unawa ng mga tanong, mas nalilinang ang pagbibigay ng wastong pang-unawa sa mga katanungan at nalilinang ang mabilis na pagiisip dahil sa mga nakalahad na clues ay mayroong $(\mathrm{M}=4.70, \mathrm{SD}=$ 0.48). Bagaman napansin na lubhang mataas na antas ng pagtanggap, ang pahayag na may pinakamababang marka ay madaling napoproseso ang mga itinuturo at pinagagaan ang pagbibigay ng interbensiyon sa mga mag-aaral na mababa ang antas ng kakayahan sa pagunawa ng teksto ay mayroong $(\mathrm{M}=4.60, \mathrm{SD}=0.70)$.

Sa kabuuan ay may lubhang mataas na antas ng pagtanggap at sa pananaw ng mga tagatugon, mabilis ang paraan ng pagbibigay ng mga katanungan sa magaaral ay nakakuha ng $(\mathrm{M}=4.67, \mathrm{SD}=0.52)$ at nakapagbibigay-aliw sa proseso ng pagtuturo at pagkatuto at pag-unawa ay mayroong $(\mathrm{M}=4.61, \mathrm{SD}=$ 0.64). Bagaman napansin na lubhang mataas na antas ng pagtanggap, ang pahayag na may pinakamababang marka ay Madaling napoproseso ang mga itinuturo ay mayroong $(\mathrm{M}=4.39, \mathrm{SD}=0.98)$.

May kabuuang mean na 4.52, standard deviation na 0.768 at ipinapakita na ang antas ng paggamit ng Basa-Pang-unawa App bilang interbensiyon sa Pagkatuto batay sa Pagsasanay ay may puna na lubos na sumasang-ayon at may literal na paliwanag na lubhang mataas.

Batay kay Caballero salig kay Burden (2011) ang pagsasanay ay proseso na kung ang guro ay gumagamit ng impormasyon halaw sa maraming pinagkukunan upang humantong sa halaga ng paghusga. Sa gayon ay makita ang resulta ng pagsasanay na magiging basehan sa gagawing panghuhusga sa natapos na gawain.

Talahanayan 3 ay naglalaman ng Antas ng paggamit ng Basa-Pang-unawa App bilang interbensiyon sa Pagkatuto batay sa Layunin

Talahanayan 3. Antas ng paggamit ng Basa-Pang-unawa App bilang interbensiyon sa Pagkatuto batay sa Layunin

\begin{tabular}{|c|c|c|c|c|c|c|c|}
\hline \multirow[t]{2}{*}{ Mga Pahayag } & \multicolumn{2}{|c|}{ Mag-aaral } & \multicolumn{2}{|c|}{ Guro } & \multicolumn{3}{|c|}{ Kabuuan } \\
\hline & Mn & SD & Mn & SD & $\mathbf{O M}$ & SD & Puna \\
\hline Lohikal at organisado ng nilalaman. & 4.49 & 0.64 & 4.60 & 0.84 & 4.51 & 0.68 & Lubos na sumasang-ayon \\
\hline $\begin{array}{l}\text { Napapaunlad ang kanilang pag-unawa sa paggamit } \\
\text { ng aplikasyon. }\end{array}$ & 4.44 & 0.68 & 4.80 & 0.42 & 4.51 & 0.65 & Lubos na sumasang-ayon \\
\hline $\begin{array}{l}\text { Nakatutulong ang aplikasyon sa mga mag-aaral } \\
\text { kahit walang internet koneksiyon. }\end{array}$ & 4.33 & 1.06 & 4.70 & 0.48 & 4.41 & 0.98 & Lubos na sumasang-ayon \\
\hline $\begin{array}{l}\text { Nakabatay sa kurikulum ang layunin at gawain na } \\
\text { nakapaloob sa aplikasyon }\end{array}$ & 4.46 & 0.68 & 4.70 & 0.48 & 4.51 & 0.65 & Lubos na sumasang-ayon \\
\hline $\begin{array}{l}\text { Nabibigyang pansin ang aplikasyon at ang buong } \\
\text { layunin nito. }\end{array}$ & 4.46 & 0.85 & 4.70 & 0.48 & 4.51 & 0.79 & Lubos na sumasang-ayon \\
\hline $\begin{array}{l}\text { Nagkakaroon ng higit na kabatiran ang mga mag- } \\
\text { aaral sa kamoprehensiyon mula sa aplikasyon. }\end{array}$ & 4.36 & 0.74 & 4.70 & 0.48 & 4.43 & 0.71 & Lubos na sumasang-ayon \\
\hline $\begin{array}{l}\text { Nabibigyang halaga ng mga mag-aaral ang } \\
\text { pagbasa sa paggamit ng aplikasyon. }\end{array}$ & 4.49 & 0.68 & 4.70 & 0.48 & 4.53 & 0.65 & Lubos na sumasang-ayon \\
\hline $\begin{array}{l}\text { Nahihikayat ang mag-aaral na magbasa na kahit } \\
\text { anong oras gamit ang aplikasyon. }\end{array}$ & 4.62 & 0.67 & 4.80 & 0.42 & 4.65 & 0.63 & Lubos na sumasang-ayon \\
\hline $\begin{array}{l}\text { Napapalalim ang mga kaalaman ng mga mag-aaral } \\
\text { hinggil sa aralin na kanilang binabasa. }\end{array}$ & 4.46 & 0.82 & 4.70 & 0.48 & 4.51 & 0.77 & Lubos na sumasang-ayon \\
\hline $\begin{array}{l}\text { Nakatutulong upang makahikayat ang mga mag- } \\
\text { aaral na magkaroon ng interes sa pagbasa. }\end{array}$ & 4.54 & 0.88 & 4.80 & 0.42 & 4.59 & 0.81 & Lubos na sumasang-ayon \\
\hline \multicolumn{8}{|l|}{$\begin{array}{l}\text { Overall Mean: } 4.52 \\
\text { Standard Deviation: } 0.735 \\
\text { Literal na paliwanag: } \text { Lubhang Mataas }\end{array}$} \\
\hline
\end{tabular}




\title{
EPRA International Journal of Research and Development (IJRD)
}

Volume: 6 | Issue: 7 | July 2021

\author{
- Peer Reviewed Journal
}

Palatandaan

$\begin{array}{lll}\text { Sukatan } & \text { Saklaw } & \text { Puna } \\ 5 & 4.20-5.00 & \text { Lubos na sumasang-ayon } \\ 4 & 3.40-4.19 & \text { Sumasang-ayon } \\ 3 & 2.60-3.39 & \text { Katamtamang Sumasang-ayon } \\ 2 & 1.80-2.59 & \text { Hindi sumasang-ayon } \\ 1 & 1.00-1.79 & \text { Lubos na Hindi sumasang-ayon }\end{array}$

May lubhang mataas na antas ng pagtanggap sa pananaw ng mga mag-aaral, nahihikayat ang mga magaaral na magbasa na kahit anong oras gamit ang aplikasyon ay nakakuha ng $(\mathrm{M}=4.62, \mathrm{SD}=0.67)$ at nakatutulong upang makahikayat ang mga mag-aaral na magkaroon ng interes sa pagbasa ay mayroong $(\mathrm{M}=$ 4.54, $\mathrm{SD}=0.88)$. Bagaman napansin na lubhang mataas na antas ng pagtanggap, ang pahayag na may pinakamababang marka ay nakatutulong ang aplikasyon sa mga mag-aaral kahit walang internet koneksiyon ay mayroong $(\mathrm{M}=4.33, \mathrm{SD}=1.06)$.

At may lubhang mataas na antas ng pagtanggap sa pananaw ng mga guro, napapaunlad ang kanilang pag-unawa sa paggamit ng aplikasyon, nahihikayat ang mag-aaral na magbasa na kahit anong oras gamit ang aplikasyon at nakatutulong upang makahikayat ang mga mag-aaral na magkaroon ng interes sa pagbasa ay nakakuha ng $(\mathrm{M}=4.80, \mathrm{SD}=0.42)$ at nakatutulong ang aplikasyon sa mga mag-aaral kahit walang internet koneksiyon, nakabatay sa kurikulum ang layunin at gawain na nakapaloob sa aplikasyon, nabibigyang pansin ang aplikasyon at ang buong layunin nito, nagkakaroon ng higit na kabatiran ang mga mag-aaral sa kamoprehensiyon mula sa aplikasyon, nabibigyang halaga ng mga mag-aaral ang pagbasa sa paggamit ng aplikasyon at napapalalim ang mga kaalaman ng mga mag-aaral hinggil sa aralin na kanilang binabasa ay mayroong $(\mathrm{M}=4.70, \mathrm{SD}=0.48)$. Bagaman napansin na lubhang mataas na antas ng pagtanggap, ang pahayag na may pinakamababang marka ay lohikal at organisado ng nilalaman ay mayroong $(\mathrm{M}=4.60, \mathrm{SD}=$ $0.84)$.

\author{
Literal na paliwanag \\ Lubhang Mataas \\ Mataas \\ Katamtamang Taas \\ Mababa \\ Lubos Mababa
}

Sa kabuuan ay may lubhang mataas na antas ng pagtanggap at sa pananaw ng mga tagatugon, Nahihikayat ang mag-aaral na magbasa na kahit anong oras gamit ang aplikasyon ay nakakuha ng $(\mathrm{M}=4.65$, $\mathrm{SD}=0.63$ ) at nakatutulong upang makahikayat ang mga mag-aaral na magkaroon ng interes sa pagbasa ay mayroong $(\mathrm{M}=4.59, \mathrm{SD}=0.81)$. Bagaman napansin na lubhang mataas na antas ng pagtanggap, ang pahayag na may pinakamababang marka ay nakatutulong ang aplikasyon sa mga mag-aaral kahit walang internet koneksiyon ay mayroong $(\mathrm{M}=4.41$, $\mathrm{SD}=0.98)$.

May kabuuang mean na 4.52, standard deviation na 0.735 at ipinapakita na ang antas ng paggamit ng Basa-Pang-unawa App bilang interbensiyon sa Pagkatuto batay sa Layunin ay may puna na lubos na sumasang-ayon at may literal na paliwanag na lubhang mataas.

Talahanayan bilang apat ay nagpapakita naman ng antas ng pagganap ng mga mag-aaral sa asignaturang Filipino batay sa paunang pagsusulit, sa kabuoang apatnapung tagatugon, ang marka na "5 hanggang 16 " ay nakakuha ng pinakamataas na bilang na dalawampu at tatlo (23) o 51.11\% ng kabuuang tumugon at may mapaglarawang katumbas na $D i$ gaanong Mahusay. At ang marka na "20 hanggang 25 ” ay mayroong bilang na labing anim (16) o $35.56 \%$ ng kabuuang tumugon at may mapaglarawang katumbas na Mahusay. Habang ang marka na "17 hanggang 19" ay nakakuha ng pinakamababang bilang na anim (6) o $13.33 \%$ ng kabuuang tumugon at may mapaglarawang katumbas na Katamtamang Mahusay.

Talahanayan 4. Antas ng pagganp ng mga mag-aaral sa asignaturang Filipino batay sa pauna at panapos na pagsusulit

\begin{tabular}{|l|c|c|c|c|l|}
\hline \multirow{2}{*}{ Marka } & \multicolumn{2}{|c|}{ Paunang Pagsusulit } & \multicolumn{2}{c|}{ Panapos na Pagsusulit } & Mapaglarawang Katumbas \\
\cline { 2 - 6 } & Bilang & Bahagdan & Bilang & Bahagdan & \\
\hline $29-30$ & 0 & 0.00 & 2 & 4.44 & Pinakamahusay \\
\hline $26-28$ & 0 & 0.00 & 2 & 4.44 & Higit na Muhusay \\
\hline $20-25$ & 16 & 35.56 & 19 & 42.22 & Mahusay \\
\hline $17-19$ & 6 & 13.33 & 7 & 15.56 & Katamtamang Mahusay \\
\hline $5-16$ & 23 & 51.11 & 15 & 33.33 & Di- gaanong Mahusay \\
\hline $2-4$ & 0 & 0.00 & 0 & 0.00 & Di Lubhang Mahusay \\
\hline $0-1$ & 0 & 0.00 & 0 & 0.00 & Di Mahusay \\
\hline
\end{tabular}


SJIF Impact Factor 2021: 8.013| ISI I.F.Value:1.241| Journal DOI: 10.36713/epra2016 ISSN: 2455-7838(Online) EPRA International Journal of Research and Development (IJRD)

Volume: 6 | Issue: 7 | July 2021

- Peer Reviewed Journal

\begin{tabular}{|c|c|c|c|}
\hline TOTAL & 100.00 & 45 & 100.00 \\
\hline $\begin{array}{l}\text { Weighted } \\
\text { Mean }\end{array}$ & 17.00 & & 19.18 \\
\hline Pinakamababang Marka & 9 & & 10 \\
\hline Pinakamataas na Marka & 25 & & 29 \\
\hline $\begin{array}{l}\text { Standard } \\
\text { Deviation }\end{array}$ & 4.285 & & 5.167 \\
\hline Literal na Paliwanag & Mahusay & & Mahusay \\
\hline
\end{tabular}

\section{Palatandaan:}

Sukatan

$96 \%-100 \%$

$86 \%-95 \%$

$66 \%-85 \%$

$55 \%-65 \%$

$15 \%-54 \%$

$5 \%-14 \%$

$0 \%-4 \%$
Literal na Paliwanag

Pinakamahusay

Higit na Mahusay

Mahusay

Katamtamang Mahusay

Di-gaanong mahusay

Di lubhang mahusay

Di-mahusay
May kabuuang (Weighted Mean $=17.00, S D=$ 4.285) at (pinakamababang marka $=9$, pinakamataas na marka $=25$ ) ipinapakita na ang antas ng pagganap ng mga mag-aaral sa asignaturang Filipino batay sa paunang pagsusulit ay may mapaglarawang katumbas na Mahusay

Habang ang antas ng pagganap ng mga magaaral sa asignaturang Filipino batay sa panapos pagsusulit, sa kabuuang apatnapu at lima tagatugon, ang marka na "20 hanggang 25" ay nakakuha ng pinakamataas na bilang na labing siyam (19) o $42.22 \%$ ng kabuuang tumugon at may mapaglarawang katumbas na Mahusay. At ang marka na "5 hanggang 16 " ay mayroong bilang na labinglima (15) o $33.33 \%$ ng kabuuang tumugon at may mapaglarawang katumbas na Di Gaanong Mahusay. Habang ang marka na "26 hanggang 28", "29 hanggang 30" ay nakakuha ng pinakamababang bilang na tig-dalawa (2) o $4.44 \%$ ng kabuuang tumugon at may mapaglarawang katumbas na Pinakamahusay at Higit na Mahusay.

May kabuuang (Weighted Mean $=19.18, S D=$ 5.167) at (pinakamababang marka $=10$, pinakamataas na marka $=29$ ) ipinapakita na ang antas ng performans ng mga mag-aaral sa asignaturang Filipino batay sa panapos na pagsusulit ay may mapaglarawang katumbas na Mahusay.

Talahanayan 5 ay nagpapakita ng pagkakaiba ng antas ng pagganap ng mga mag-aaral batay sa pauna at panapos na pagsusulit. Ang datos ay tinuos gamit ang ttest. Ang paunang pagsusulit ay ipinares sa panapos na pagsusulit para makita malaman ang pagkakaiba sa performans ng mga Mag aaral batay sa paunang at panapos na pagsusulit.

Talahanayan 5. Makabuluhang pagkakaiba ng antas ng Pagganap ng mga Mag-aaral batay sa pauna at panapos na pagsusulit

\begin{tabular}{|l|l|l|l|l|l|}
\hline Pagsusulit & Mean & $\begin{array}{l}\text { Computed t- } \\
\text { value }\end{array}$ & $\begin{array}{l}\text { Critical } \\
\text { t-value }\end{array}$ & p-value & Analysis \\
\cline { 1 - 2 } & 17.00 & 2.1764 & 1.6629 & 0.0162 & Makabuluhan \\
\hline Panapos & 19.18 & & & \\
\hline
\end{tabular}

Ang computed t-value na 2.1764 ay higit na mataas sa critical t-value na 1.6629 na mayroong suportang tinuos p-value na 0.0162 , ipinapakita ng datos na may pagtaas sa performans ng mag-aaral at ang analisis ay makabuluhan

Base sa datos na nakalap, ipinapakita nito na "may makabuluhang pagkakaiba ng antas ng performans ng mga mag-aaral batay sa pauna at panapos na pagsusulit" at 0.05 antas ng kabuluhan. At ipinapakita din nito na ang walang bisang palagay na "Walang makabuluhang pagkakaiba ng antas ng performans ng mga mag-aaral batay sa pauna at panapos na pagsusulit" ay huwag tanggapin, ipinapakita nito na "may makabuluhang" pagkakaiba sa pagitan nila. 
Talahanayan 6 ay nagpapakita ng epekto ng paggamit ng Basa-Pang-unawa App bilang interbensiyon sa Pagkatuto sa Performans ng mga magaaral sa Asignaturang Filipino. Ang datos ay tinuos gamit ang F-test. Ang paggamit ng Basa-Pang-unawa
App bilang interbensiyon ay ipinares sa Pagkatuto sa Performans ng mga mag-aaral sa Asignaturang Filipino para makita at malaman ang epekto sa performans ng mga Mag aaral.

Talahanayan 6. Makabuluhang epekto ng paggamit ng Basa-Pang-unawa App bilang interbensiyon sa Pagkatuto sa Performans ng mga mag-aaral sa Asignaturang Filipino

\begin{tabular}{|l|l|l|l|l|}
\hline $\begin{array}{l}\text { Basa-Pang- } \\
\text { unawa App }\end{array}$ & \multirow{2}{*}{ Pagkatuto } & F-value & p-value & Analysis \\
\cline { 1 - 3 } Nilalaman & Pagganap & 3.7949 & 0.0581 & Makabuluhan \\
\cline { 1 - 3 } Pagsasanay & & 1.7543 & 0.1925 & Makabuluhan \\
\cline { 1 - 1 } Layunin & & 1.6960 & 0.1999 & Makabuluhan \\
\hline
\end{tabular}

Ang F-value na 3.7949 para sa nilalaman, 1.7543 para sa pagsasanay at 1.6960 para sa layunin at mayroong suportang tinuos p-value na $0.0581,0.1925$, 0.1999 , ipinapakita ng datos na ang analisis ay makabuluhan.

Base sa datos na nakalap, ipinapakita nito na "may makabuluhang epekto ng paggamit ng Basa-Pangunawa App bilang interbensiyon sa Pagkatuto sa Performans ng mga mag-aaral sa Asignaturang Filipino" at 0.05 antas ng kabuluhan. At ipinapakita din nito na ang walang bisang palagay na "Walang makabuluhang epekto ng paggamit ng Basa-Pangunawa App bilang interbensiyon sa Pagkatuto sa Performans ng mga mag-aaral sa Asignaturang Filipino" ay huwag tanggapin, ipinapakita nito na "may makabuluhang" epekto sa pagitan nila.

\section{KONKLUSYON}

Sa pamamagitan ng mga inilahad na pagbubuo at pagkuha ng datos, nabuo ang konklusyon. Ipinapakita nito na "may makabuluhang epekto ng paggamit ng Basa-Pang-unawa App bilang interbensiyon sa Pagkatuto sa pagganap ng mga magaaral sa Asignaturang Filipino. Ang hinuhang walang bisang palagay na "Walang makabuluhang epekto ng paggamit ng Basa-Pang-unawa App bilang interbensiyon sa Pagkatuto sa Performans ng mga magaaral sa Asignaturang Filipino" ay huwag tanggapin, sapagkat ipinapakita nito na "may makabuluhang" epekto sa pagitan nila. Patunay lamang ito na ang malaking maidudulot sa kakayahan ng mga mag-aaral ang pagbuo ng mga Apps. At maaring magamit bilang isang interbensyon sa pagbasa upang mapataas pa ang kanilang komprehensyon.

\section{PASASALAMAT}

Sa paaralang Laguna State Polytechnic University, Main Campus saludo po ako sa inyo dahil sa patuloy na pagtupad ng aming pangarap;

Hon. Mario R. Briones, Ed. D, Pangulo ng Laguna State Polytechnic University, sa patuloy na pagsuporta at pagsulong ng iba't ibang uri ng pananaliksik upang makaagapay sa patuloy na pagunlad ng edukasyon at sa kapaki-pakinabang ng pinamamahalaan;

Prof. Florhaida V. Pamatmat, Ed. D., Dekana ng Kolehiyo ng Edukasyon Pangguro at Aplayd Riserts, na patuloy ang suporta;

Sierra Marie S. Aycardo, Ph. D., gurong tagapayo, sa kanyang walang sawang paglalaan ng oras, paggabay sa panahon na kailangan ka namin.Isa kayo sa naging inspirasyon ng aking pag-aaral, lagi kayong naagapay upang matagumapy ang pananaliksik na ito;

Evelyn A. Sunico, Ed. D., na nagsilbing istatistisyan, sa kanyang kahusayan sa pagpapayo at pagpapaliwanag sa mga angkop na istatistikal na mga instrumento para sa pag-aaral;

Teresita C. Elayba, Ed. D., Subject Specialist, sa kanyang dedikasyon, oras, at panahon na suriin ang nilalaman at mahahalagang impormasyon $\mathrm{ng}$ pananaliksik na ito;

Rosario G. Catapang, Ph.D., Technical Editor, sa kanyang buong husay na paggabay sa aspetong teknikal para sa ikaaayos ng pananaliksik na ito;

Eric P. Castillo, Ed. D., eksternal na panel ng mananaliksik, sa paglalaan ng oras at panahon upang maisaayos ang pananaliksik na ito.

Benjamin O. Arjona, Ed. D., na nagsilbing eksternal na istatistisyan, sa kanyang kahusayan sa pagsasaayos at pagpapaliwanag, ng mga interpretasyon ng mga datos na nagbigay kalinawan sa pananaliksik na ito; 


\section{SJIF Impact Factor 2021: 8.013| ISI I.F.Value:1.241| Journal DOI: 10.36713/epra2016 ISSN: 2455-7838(Online) EPRA International Journal of Research and Development (IJRD)}

Rea C. Bunan, katuwang na punongguro I ng Pag-asa National High School, sa pagbibigay ng payo sa mananaliksik at pagbibigay ng pahintulot para magamit ang mga mag-aaral bilang mga respondente upang makalap ang mga kinakailangang datos;

Sa mga mag-aaral ng 7-MDL-1 sa Pag-asa National High School, sa maayos na pakikiisa at pagsasagot sa talatanungan upang makalap ang mahahalagang datos;

Sa mga aking na katrabaho sa Pag-asa National High School, lalong-lalo sa ulongguro ng aming departamento na si Gng. Jedie A. Mendoza at kina Harold Bawalan, Jayson R. Salvador, at Sheryl B. Zarsadias na sa pagiging inspirasyon at patuloy na pagbibigay ng lakas sa mga panahon na nawawalan ng tiwala sa sarili ang mananaliksik;

Hindi magiging matagumpay ang pag-aaral na ito kung hindi dahil sa inyong lahat.

\section{PINAGKUNAN}

1. Abrasaldo, E. (2014) Epekto ng Paglalaro ng Computer Games Isang Pag-aaral. Sa Mababang Paaralan Ng San Isidro Elementary School.

2. Agno G. (2017) Kabisaan Ng Mga Estratehiya Sa Pagpapaunlad Ng Masusing Pag -iisip At Ang Kaugnayan Nito Sa Akademikong Performans Batay sa Panukat Na Gawain Ng Mga Mag - aaral Ng Grade 10.

3. Aganon, $R$, Cura, A, Manzano, D (2019) Filipino sa Iba't ibang Disiplina St.Andrew Publishing House, Diliman Quezon City

4. Aguiflor, D. (2019). Paggamit ng wikabulary game sa pagpapaunlad ng talasalitaan ng mga magaaral. LSPU - Santa. Cruz, Laguna.

5. Bergonia, D. (2020). Teknolohiya sa Gitna ng Pandemya www.sdo-meycauayan.com

6. Buwan ng Pagbasa 2014: Nasa Pagbasa ang Pagasa matanglawin 2014November 3, 2014, The Manila Journal, https://themanilajourno.wordpress.com/2014/11/03 /buwan-ng-pagbasa-2014-nasa-pagbasa-ang-pagasal

7. Balaba, M. (2015) Digitized Lesson sa Filipno: Tugon sa Pangangailangan ng Ika-21 siglong Kasanayan, Pagsipat sa Epekto NIto sa Pedagohiya ng $\mathrm{mg}$ guro at pagkatuto ng Mag-aaral

8. Blanca, G. (2021) Epekto ng Teknolohiya sa Pagkaunawa sa Bokabularyong Filipino ng mga Mag-aaral sa Baitang 7-daisy sa Mataas na Pambansang Paaralan ng Alitagtag.

9. Badayos, P. (2012) Metodolohiya sa Pagtuturo ng Wika (Mga Teorya, Simulain at Estratehiya).Grandbook Publishing House Inc.

10. Bagayanan, (2015) "Module on Types of Sentences According to Purpose”.
11. Blaza, J. G. (2015). "Development and Validation of Module in Teaching Selected Topics in English." Castillo, A. (2016)." Teacher Made e-Learning Module in Social Science".

12. Bernardino, C (2014). Makabagong Pagtuturo.Manila: $C \&$ E Publication

13. Cubos, L., Jusayan, C., Palma, E., (2019) Pananaliksik Patungkol sa Isyu at mga Suliranin sa Pag-unawa sa Pagbasa at sa Kakayahan sa Pagsulat sa mga Mag-aaral sa Jesus is Lord Colleges, Foundation inc.: Batayan sa Programang Pangkaunlaran

14. Carzon, M. (2016). Komiks Mungkahing Pantulong na kagamitan pampagtuturo para sa Filipino, Baitang 8. Antipolo Campus

15. Cogo, D. (2014). Epekto ng Teknolohiya sa Pagaaral ng mga Mag-aaral. Kolehiyo ng SKSSU Kalamansig, Sultan Kudarat

16. Cruz, I. (2013). Ang ating Panitikan. JMC Press, Inc. Quezon City.

17. De Guzman, N. (2012). Kagamitang Pampagtutro Paano ka Gagawin/Ginawa? Saint Loius University.

18. De Guzman, M. A. (2015) "Worksheet s in Teaching Mathematics for Second Graders in Selected Schools in Bay, Laguna, School Year 2014-2015

19. De Guzman, N. (2012). Kagamitang Pampagtutro Paano ka Gagawin/ Ginawa?. Saint Loius University.

20. Gabrido (2014). Principles of Modular Approach. Mandaluyong City

21. Himmel, D. (2011). Readiness Assessment Test. Manila Phoenix Publishing House Inc.

22. Julian, (2012). Evaluation of Teacher Training Program in the Division of Laguna: Unpublished Doctoral Dissertation, Polytechnic University

23. Kinsey (2013) "History of Examination" Kentucky, Examination Journal

24. Khan, M. (2010), Teachers Pedagogical Design for Technology Supported Collective Inquiry a National Computers and Educationof the Philippines, ManilaLacson, D. (2020). Kabisaan ng Paggamit ng Kontekstuwalisadong Aralin sa Pagtuturo ng Filipino sa Baitang 7: Isang Eksperimental na Pagaaral

25. Lodriga, J (2019) Kabisaan sa Paggamit ng Interbensyon sa Pagbasa at Kaugnayan nito sa Performans ng Mag-aaral sa Pagbasa ng mga Kontemporaryong Teksto

26. Magnaye, H. (2016), Epekto ng Paggamit ng Iba't Ibang Estratehiya sa Pagtuturo ng Asignaturang Filipino sa Pagkatuto ng mga Mag-aaral na nasa Ikasampung Baitang, Castor Alviar National High School Lungsod ng Calamba

27. Perkins, M. (2015), Becoming A Teacher Of Reading, Thousand Oaks California Sage Publication, Ltd.Parker, E. (2010). Ideya at Istilo sa Sanaysay. Quezon City, Rex Bookstore. Rex Publishing Corp. Inc. 


\section{EPRA International Journal of Research and Development (IJRD)}

28. Paule, A. (2015). Iba't ibang Pamamaraan sa Pagkatutong mga Makrong Kasanayan Pangwika sa Filipino I ng mga Mag-aaral sa Unang Taon sa Kolehiyo sa STI College Campus

29. Salandanan, G. (2012). "Methods of Teaching", Quezon City, Lorimar Publishing. UP Diksyunaryong Filipino (2010) Ikalawang Edisyon, Anvil PublishingInc. Diliman, Quezon City

30. Sevilla, E. Jr. (2013). Epekto ng Pamamaraang Computer - Aided Instruction sa Pagtuturo ng Filipino. Bataan Peninsula State University, Balanga City. Marso.

31. Sevilla, E Jr. (2013). Epekto ng Pamamaraang Computer - Aided Instruction sa Pagtuturo ng Filipino. Bataan Peninsula State University, Balanga City. Marso

32. Chang, H. 2010. The relationship between extrinsic/intrinsic motivation and language learning strategies among college students of English in Taiwan, Unpublished doctoral dissertation, Ming Chuan University, Taiwan. Retrieved on January 25, 2020 at http://www.wjeis.org/FileUpload/ds217232/File/09. mehmet_emin_uslu_.pdf.

33. Epekto ng Multimedia sa Pang-akademikong Kasanayan ng mga mag-aaral sa Departamento ng Hayskul sa La Consolacion College Tanauan( (2018) www.wordpress.com

34. "Evaluation and Selection of Learning Resources: A Guide" (2018).Department of Education and Early Childhood Development (English Program)

35. Liwanag, L. Teorya at Pananaw sa Pagtuturo ng Pagbasa. Setyembre 17, 2012. http:www.slideshare.net

36. Pisa result, (2018). https://www.oecd.org/pisa/publications/pisa-2018results.htm

37. Reyes, E. (2018). Makabagong Teknilohiya sa Edukasyon www.depedbataan.com

38. Ramos, J (2018) Kasanayan sa Pagbasa: Sandata sa pagpanday ng Karunungan. www.depedbataan.com

39. Roque, P (2015). Positibo at negatibong dulot ng Komputer sa mga mag-aaral. www.coursehero.com/file/p5tgsh3/

40. Tapang, $R \quad G$. (2018.) Teknolohiya sa KagamitangPampagtuturo.www.depedbataan.com

41. Veloso, B. (2019), Paano Sanayin ang bata sa Pagbabasa. Abs-cbn Teleradyo

42. Vhalerie, P. (2015) Paggamit ng Teknolohiya sa Edukasyon. www.wordpress.com 